\title{
Relapsing or refractory idiopathic thrombotic thrombocytopenic purpura-hemolytic uremic syndrome: the role of rituximab
}

\author{
Domenica Caramazza, Gerlando Quintini, Ignazio Abbene, Alessandra Malato, Giorgia Saccullo, \\ Lucio Lo Coco, Rosa Di Trapani, Roberto Palazzolo, Rita Barone, Giuseppina Mazzola, Sergio Rizzo, \\ Paolo Ragonese, Paolo Aridon, Vincenzo Abbadessa, and Sergio Siragusa
}

Idiopathic thrombotic thrombocytopenic purpurahemolytic uremic syndrome (TTP-HUS) is a rare disease responsive to treatment with plasma exchange (PE) but with a high percentage of relapse or refractory patients. A severe deficiency of ADAMTS-13 $(<5 \%$ of normal activity), congenital or caused by an autoantibody, may be specific for TTP and it has been proposed that severe ADAMTS-13 deficiency now defines TTP. B cells play a key role in both the development and the perpetuation of autoimmunity, suggesting that B-cell depletion could be a valuable treatment approach for patients with idiopathic TTP-HUS. This review of the literature focuses on the role of rituximab, a chimeric monoclonal antibody directed against CD20 antigen expressed by B lymphocytes, in patients with relapsing or refractory TTP-HUS with or without ADAMTS-13 deficiency, suggesting that rituximab may produce clinical remission in a significant proportion of patients. Rituximab therapy reduces plasma requirement and avoids complications related to salvage-immunosuppressive therapy. In conclusion, rituximab provides an effective, well-tolerated, and safe treatment option for patients with idiopathic TTPHUS, thus giving an alternative approach to the current treatment based on PE.
$\mathrm{T}$ hrombotic thrombocytopenic purpura (TTP) is a rare disorder characterized by thrombocytopenia, microangiopathic hemolytic anemia, neurologic and renal abnormalities, and fever; however, since the above-reported diagnostic criteria do not distinguish TTP from hemolytic uremic syndrome (HUS), the comprehensive term TTP-HUS has been found to be more suitable. ${ }^{1}$ In the absence of treatment the mortality rate is approximately $90 \%$ but decreases to $10 \%$ or less when immediate plasma exchange (PE) is initiated. ${ }^{2-8}$ Because of its dramatic effect on short- and long-term outcome, it is now suggested to begin PE even when all the above criteria, in absence of alternative diagnosis, are not fulfilled. , 3,5,8-10 $^{2}$ The evident advantage of early initiation of therapy along with the decreased diagnostic threshold has resulted in a sevenfold increase of patients treated with $\mathrm{PE}$ for TTP-HUS from 1981 to $1997 .^{11}$

TTP symptoms are related to the presence of von Willebrand factor (VWF)-rich platelet (PLT) thrombi in arterioles and capillaries. VWF is a multimeric plasma glycoprotein crucial for both PLT adhesion and aggregation, especially at the high shear rates in the

ABBREVIATIONS: HUS = hemolytic uremic syndrome; $\mathrm{PE}=$ plasma exchange; TTP $=$ thrombotic thrombocytopenic purpura.

From the Cattedra ed U.O. di Ematologia con trapianto, U.O. di Immunoematologia e Servizio Trasfusionale, and U.O. di Neurologia, Azienda Ospedaliera Universitaria Policlinico "Paolo Giaccone" di Palermo, Palermo, Italy.

Address reprint requests to: Sergio Siragusa, MD, Cattedra ed U.O. di Ematologia con trapianto, Azienda Ospedaliera Universitaria Policlinico "Paolo Giaccone" di Palermo, Via del Vespro 127, I-90127 Palermo, Italy; e-mail: sergio.siragusa@ unipa.it.

Received for publication February 20, 2010; revision received May 4, 2010, and accepted May 7, 2010.

doi: 10.1111/j.1537-2995.2010.02763.x

TRANSFUSION ${ }^{* * ; * * * * * * * *}$. 
microvasculature. The size of VWF multimers is physiologically regulated in vivo by a specific metalloprotease called ADAMTS-13 (a disintegrin-like and metalloprotease with thrombospondin Type 1 repeats). ${ }^{12}$ A severe deficiency of ADAMTS- 13 ( $<5 \%$ of normal activity) may be specific for TTP ${ }^{13}$ and it has been proposed that severe ADAMTS-13 deficiency now defines TTP. ${ }^{14,15}$ ADAMTS-13 deficiency, caused by an autoantibody, provides a possible explanation for the effectiveness of PE (removal of the autoantibody by apheresis; supply of ADAMTS-13 by plasma replacement). Although its measurements have been suggested to guide treatment decisions, ${ }^{14,16-19}$ at the present it is not possible to establish the sensitivity of ADAMTS-13 deficiency for identifying patients who may respond or not to PE. Therapy with PE should be implemented in all patients with TTP-HUS and continued until resolution of signs and/or symptoms and normalization of laboratory tests; this can require long-term therapy.$^{9-35}$ However, approximately $10 \%$ to $20 \%$ of TTPHUS patients shows lack of response; ${ }^{9}$ in those refractory patients, different types of immunosuppressive treatment have been proposed but unsuccesfully, ${ }^{14,30,31,33}$ including steroids or immunosuppressive or immunemodulating agents. ${ }^{29,33}$ It has been reported that splenectomy may induce a remission rate of $50 \%$ to $100 \%$ in refractory or relapsing TTP patients, ${ }^{30}$ but some authors reported a high rate of relapses mainly in those patients with severe ADAMTS-13 deficiency. ${ }^{9,30,34,36}$ Such findings were not confirmed by others who reported few relapses in a large cohort of TTP patients underwent splenectomy. ${ }^{31}$

Rituximab, a chimeric monoclonal antibody directed against the CD20 antigen present on B lymphocytes, is used in lymphoma patients and those with rheumatoid arthritis. ${ }^{34}$ Its action relies on clearance of B lymphocytes responsible for antibody production by complementdependent cytotoxicity, antibody-dependent cellular cytotoxicity, or directly by inducing apoptosis. ${ }^{32,34}$ The presence of ADAMTS-13 antibody-mediated deficiency makes rituximab an ideal drug in TTP-HUS, ${ }^{12}$ especially in those patients who are refractory to PE therapy. Although high promisingly, case series only have reported efficacy and safety of this anti-CD20 in TTP-HUS patients, thus leaving unresolved questions regarding target population, timing of initiation, duration of treatment, and usefulness of concomitant PE. ${ }^{35-63}$ This review examines the evidence base supporting the use of rituximab in the treatment of refractory or relapsed TTP.

\section{MATERIALS AND METHODS}

\section{Data search}

Information for this review was compiled by searching PubMed and Medline databases for articles published from October 2002 up to October 2009. Only articles published in English were considered. "Search" terms included "thrombocytopenic," "thrombotic," "purpura," "ADAMTS 13," "hemolytic," "uremic," and "syndrome" in association with "refractory," "relapsing," "plasma exchange," "rituximab," "monoclonal," "anti-CD20," and "antibody." References were chosen based on the evidence of rituximab treatment in idiopathic refractory or relapsing TTP-HUS and on the chronologic order of reporting it in the literature.

\section{Definition of outcomes}

Remission was defined as sustained normal PLT count, absence of clinical manifestations of TTP, and cessation of PE. Refractory TTP was defined as failure to achieve either a normal PLT count after 7 days of PE or deterioration in clinical symptoms despite standard therapy during the first episode of TTP. ${ }^{34}$ Relapsing TTP was defined as deterioration of clinical and laboratory findings occurred after sustained remission. ${ }^{9}$

\section{REVIEW OF THE LITERATURE}

A comprehensive list of article cited in this review is reported in Table 1. The earliest report about acute refractory TTP treated successfully with rituximab involved two cases. $^{39}$ Fankouri and coworkers ${ }^{12}$ conducted a prospective multicenter open-label study to test the efficacy of rituximab in the therapeutic or prophylactic treatment of 11 patients with TTP caused by the presence of inhibitory antibodies against ADAMTS-13. Six patients with an episode of acute refractory TTP and five patients with relapsing TTP and persistence of anti-ADAMTS-13 were treated. Target of treatment was to maintain ADAMTS-13 of more than $10 \%$. Rituximab was given in courses of four weekly doses of $375 \mathrm{mg} / \mathrm{m}^{2}$ and it led to clinical remission in all cases, decreasing to not detectable level antibodies to ADAMTS-13, and increasing ADAMTS-13 activity from $18 \%$ to $75 \%$.

The largest case series involving a first episode of acute refractory and relapsing idiopathic TTP was published by Scully and coworkers. ${ }^{49}$ Twenty-five patients received rituximab in conjunction with $\mathrm{PE}$ because of progressive clinical disease or deterioration in laboratory variables, despite intensive standard therapy. In relapsing TTP, rituximab was started if antibody to ADAMTS-13 was demonstrated during previous episodes. On admission all patients received intravenous (IV) methylprednisolone daily for 3 days. In total, 14 cases have been reported that fulfilled the criteria of acute refractory TTP, 12 cases had ADAMTS-13 activity of less than 5\%, one case had $12 \%$ enzyme activity, and one case had no measured baseline ADAMTS-13 activity but had normal ADAMTS-13 activity after 6 weeks of treatment elsewhere with PE and prednisolone. Thirteen patients had 


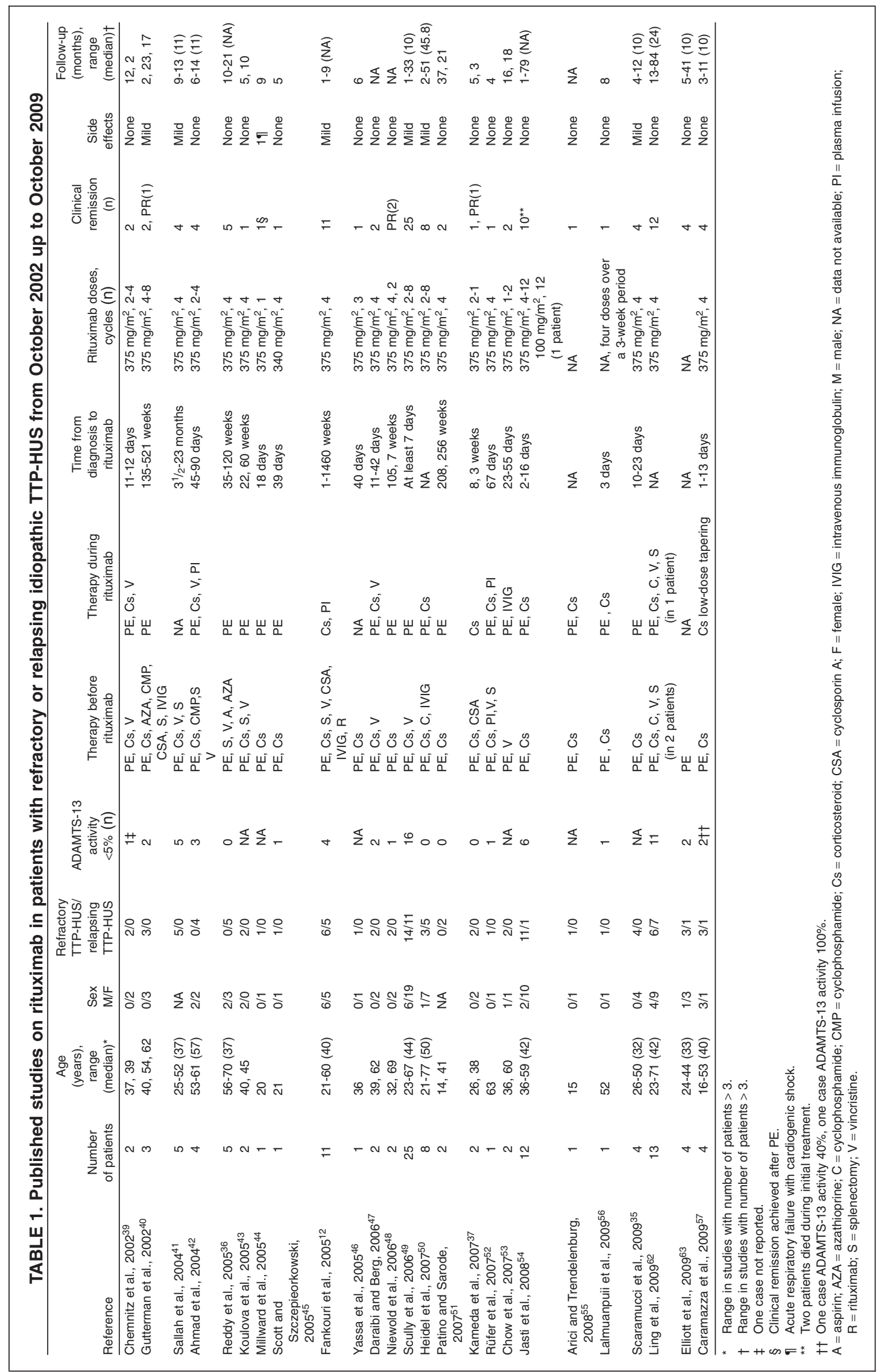


evidence of an inhibitor to ADAMTS-13 and/or IgG antibodies to ADAMTS-13 on admission. All patients received a weekly IV rituximab infusion for 4 weeks immediately after PE. The median ADAMTS-13 activity 3 months after four rituximab doses of $375 \mathrm{mg} / \mathrm{m}^{2}$ was $90 \%$ (range, $29 \%-109 \%$ ) and there was also a significant decrease in IgG antibody titer with no evidence of an inhibitor in any patient $(\mathrm{p}<0.0001)$. Rituximab determined rapid improvement of clinical features and laboratory variables within a median of 11 days after initiation of therapy; the drug was well tolerated and no relapse of TTP occurred during a median follow up of 10 months (range, 1-33 months).

Ling and coworkers ${ }^{62}$ presented 13 patients with refractory or relapsing TTP treated with rituximab. Twelve of them (92\%) achieved complete response; no subsequent relapses occurred with median follow-up of 24 months.

Subsequently Jasti and colleagues ${ }^{54}$ described 12 patients with TTP (11 with refractory and one with relapsed disease) treated with rituximab. Of the 11 patients treated during the first episode of TTP, nine maintained remission for more than 59 months (range, 1-79 months). Two patients died during treatment. Regarding patients treated because of relapsed TTP, he maintained complete remission for 2 years. Then, due to a second relapse, he was treated again with rituximab and even in this case he maintained complete remission for 22 months. Rituximab was effective and maintain remission for more than 21 months even when a third relapse occurred.

Considering all the reports present in Table 1, 76 of $118(64 \%)$ had refractory and 42 of $118(36 \%)$ had relapsed TTP. Among refractory patients 67 of 76 (88\%) achieved remission to rituximab treatment, with a median followup of 10 to 24 months. Among relapsed patients, all achieved complete remission after a median follow-up of 10 to 45.5 months. Since no specific regimen with antiCD20 has been proven to be effective in these, therapy is mainly empirical. In the majority of studies evaluated, rituximab was administrated along with PE or immunosuppressive drugs (Table 1). In the largest study in acute refractory cases, the median numbers of PEs before rituximab and after the first rituximab infusion were 13 and 9, respectively. ${ }^{49}$ In the series by Fankouri and coworkers, ${ }^{12}$ patients prospectively included during a refractory acute TTP had PE discontinued before treatment with rituximab. In place of PE, plasma infusions (15-25 mL/ $\mathrm{kg} /$ day) were continued and progressively tapered after the induction of complete remission (CR). In some cases (21/118; $18 \%$ ) complete remission was achieved after two or three infusions of rituximab at a dose of $375 \mathrm{mg} / \mathrm{m}^{2}$ at weekly intervals, while in others $(17 / 118 ; 14 \%)$ this was achieved after eight administrations. In one patient rituximab was given at $100 \mathrm{mg} / \mathrm{m}^{2}$ in 12 weekly infusions. ${ }^{54}$
Serious side effects were not reported during or after rituximab administration except in one case, 6 hours after the drug infusion when the patient presented acute respiratory failure and cardiogenic shock. ${ }^{44}$ In our experience (Table 2) in relapsed or refractory TTP-HUS (with or without ADAMTS-13 deficiency) rituximab was given at the dose of $375 \mathrm{mg} / \mathrm{m}^{2}$ a shot a week for 1 month without other drugs except steroids.

\section{DISCUSSION}

Idiopathic TTP-HUS is a life-threatening disease still difficult to properly manage. Standard therapy is PE performed daily, until resolution of symptoms and/or normalization of laboratory values (recovery of PLT count, increase of hemoglobin [Hb], decrease of lactate dehydrogenase $[\mathrm{LDH}]$, and absence of peripheral schistocytosis). The discovery that deficiency of ADAMTS-13 may be related to the severity and prognosis of idiopathic TTPHUS has now been suggested to test such marker, at the diagnosis or during remission, for identifying patients at high risk for recurrent TTP-HUS. ${ }^{15-18}$ However, some uncertainties still remain since ADAMTS-13 deficiency does not allow the detection of all patients who may be appropriately diagnosed as TTP-HUS. ${ }^{9,36,37}$ Moreover, it is not possible to establish the sensitivity of ADAMTS-13 deficiency for identifying patients who may respond or not to PE; therefore, at the present, there are no sufficient data to safely manage TTP patients on ADAMTS-13 detection.

PE is an effective treatment for TTP because of the clearance of antibodies against ADAMTS-13 protease while it is not very effective in case of secondary TTP. Consequently, it has been postulated that PE may not be effective in patients without ADAMTS-13 deficiency but some reports have been proven that it does. ${ }^{9,34,37}$ For these reasons, PE remains the standard treatment for idiopathic TTP-HUS independently from ADAMTS-13 detection. ${ }^{9}$

Despite the considerable improvement in survival with daily PE in patients with idiopathic TTP-HUS, there is a subset of patients with either delayed or absent response to this treatment. ${ }^{9-35}$ In fact, approximately $10 \%$ to $20 \%$ of TTP-HUS patients are refractory (even after several procedures) or (early) relapsed early. ${ }^{52}$ However, in these cases, additional therapy with immunosuppressive drugs (such as steroids, cyclophosphamide, or cyclosporine) has not been proven to be beneficial. ${ }^{14,30,31}$

Rituximab administration has been proven to be effective in the treatment of acute refractory or relapsing idiopathic TTP-HUS in patients with and without ADAMTS-13-inhibitory antibodies ${ }^{38-55}$ even if, in this last case, its mechanism of action is unclear. Kameda and colleagues $^{34,37}$ postulated that B-cell depletion by anti-CD20 may reduce excessive cytokine production in patients with secondary TTP and thus maintaining the level of von 


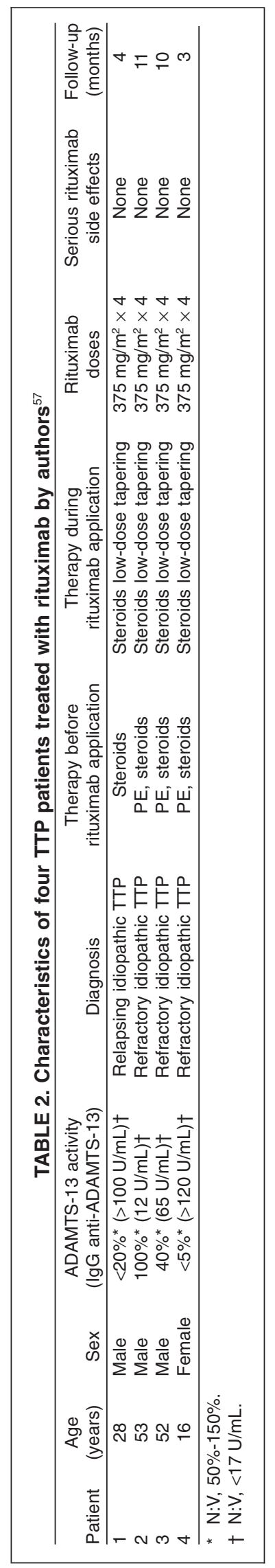

Willebrand multimers within the normal range. Similarly, this mechanism may also explain the success of PE in patients without ADAMTS-13 deficiency or in those with secondary TTP-HUS. Moreover, rituximab had determined the disappearance of ADAMTS-13 inhibitors. Thus, this drug may play a primary role in high-risk TTP patients, defined as those who maintain low levels of ADAMTS-13 and characterized by high probability of relapsing. ${ }^{64}$ This antibody might also be used as maintenance therapy in this group of patients even after a sustained clinical and laboratory remission. ${ }^{60}$ Rituximab may play also an important role as alternative treatment in patients not eligible for PE because of serious related complications such as nephropathy, ${ }^{12,43}$ pancreatitis, ${ }^{65}$ and cerebral ischemia occurring during TTP. ${ }^{66}$

Our and other results are promising about the use of rituximab in TTP patients but there is still a lack of reliable data on timing schedule, dosage, long-term maintenance and side effects. In Fig. 1 is proposed a flow chart for using rituximab according to the evidence of published studies.

Although the optimal dose of rituximab in this setting has not been fully established, standard treatment of $375 \mathrm{mg} / \mathrm{m}^{2}$ once weekly for 4 weeks looks effective and safe. ${ }^{12,36,37,39-43,45,47-52,54,56}$ The effectiveness of a different schedule of therapy, such as dose of $375 \mathrm{mg} / \mathrm{m}^{2}$ once or twice or a reduction of the single administered dose, needs further study. $37,39,42,44,46,48,50,53$

Obviously, it is necessary to balance risks and benefits of different options. PE is expensive and often associated with complications related to venous access including infection, catheter thrombosis, hypoxemia, hypotension, and transfusion reaction. ${ }^{27,28,56}$ Rituximab is usually well tolerated and reactions are usually mild without causing discontinuation of the drug. ${ }^{12,35,41,49,50}$ However, rarely potentially life-threatening complications have been reported, such as progressive multifocal leukoencephalopathy, viral infections, cardiovascular events, and renal toxicity. ${ }^{38-40,49}$

New clinical trials are now ongoing and hopefully they will furnish a response about the optimal management of refractory or relapsed TTP patients including the role of rituximab and the need for ADAMTS-13 detection. ${ }^{61,67}$

In the meantime, rituximab has been proven to be effective in the treatment of relapses and may be used in high-risk patients. ${ }^{12,36,42,49-51,54,57,60,62,63}$ Furthermore this anti-CD20 may be a therapeutic option in idiopathic TTPHUS patients, with or without ADAMTS13 deficiency, who fail to respond after 7 to 14 days of standard treatment.

\section{CONFLICT OF INTEREST}

The author(s) certify that they have no affiliation with or financial involvement in any organization or entity with a direct financial interest in the subject matter or materials discussed in this 


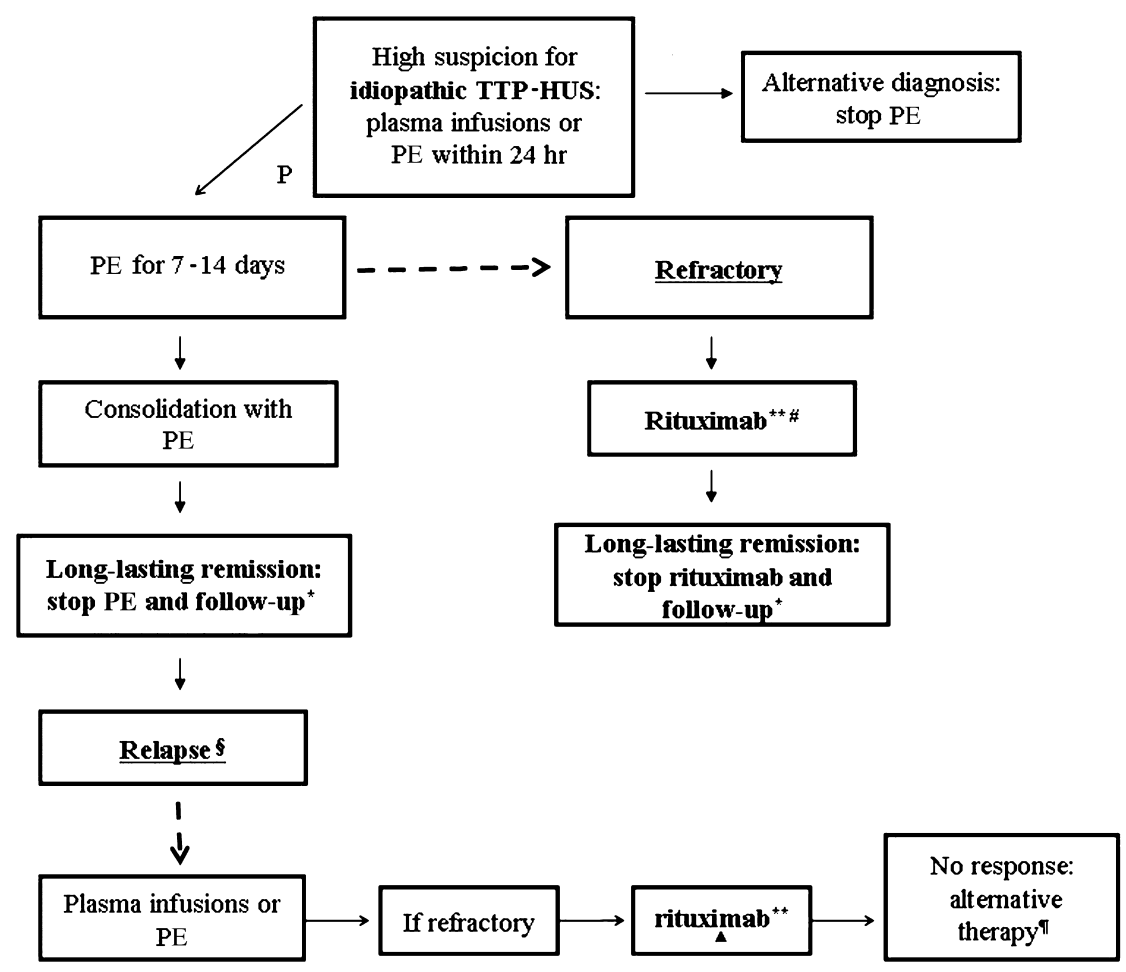

Fig. 1. Idiopathic TTP-HUS management and rituximab role. *Follow-up with periodic controls: PLT count, Hb, LDH, ADAMTS-13 activity, and IgG anti-ADAMTS 13 titer. **Four weekly doses of rituximab at $375 \mathrm{mg} / \mathrm{m}^{2}$. \#Consolidation and maintenance therapy with rituximab can be used in high-risk patients. \$Relapse after remission obtained with PE or rituximab. $\triangle$ Rituximab may work even in patients originally refractory to $\mathrm{PE}$ and treated with rituximab. ๆExperimental drugs.
6. Hayward CP, Sutton DM, Carter WH Jr, Campbell ED, Scott JG, Francombe WH, Shumak KH, Baker MA. Treatment outcomes in patients with adult thrombotic thrombocytopenic purpura-hemolytic uremic syndrome. Arch Intern Med 1994; 154:982-7.

7. Elkins SL, Wilson PP, Files JC, Morrison FS. Thrombotic thrombocytopenic purpura: evolution across 15 years. J Clin Apheresis 1996;11: 173-5.

8. Lara PN Jr, Coe TL, Zhou H, Fernando L, Holland PV, Wun T. Improved survival with plasma exchange in patients with thrombotic thrombocytopenic purpura-hemolytic uremic syndrome. Am J Med 1999;107:573-9.

9. Vesely SK, George JN, Lämmle B, Studt JD, Alberio L, El-Harake MA, Raskob GE. ADAMTS13 activity in thrombotic thrombocytopenic purpura-hemolytic syndrome: relation to presenting features and clinical outcomes in a prospective cohort of 142 patients. Blood 2003;102:60-8.

10. George JN. How I treat patients with thrombotic thrombocytopenic purpura-hemolytic uremic syndrome. Blood 2000;96:1223-9. manuscript (e.g., employment, consultancies, board membership, stock ownership, honoraria).

\section{REFERENCES}

1. Amorosi EL, Ultmann JE. Thrombotic thrombocytopenic purpura: report of 16 cases and review of the literature. Medicine 1966;45:139-59.

2. Rock GA, Shumak KH, Buskard NA, Blanchette VS, Kelton JG, Nair RC, Spasoff RA. Comparison of plasma exchange with plasma infusion in the treatment of thrombotic thrombocytopenic purpura. N Engl J Med 1991;325: 393-7.

3. Rock G, Shumak K, Kelton J, Blanchette VS, Buskard N, Nair R, Spasoff R. Thrombotic thrombocytopenic purpura: outcome in 24 patients with renal impairment treated with plasma exchange. Transfusion 1992;32:710-4.

4. Bell WR, Braine HG, Ness PM, Kickler TS. Improved survival in thrombotic thrombocytopenic purpura-hemolytic uremic syndrome. N Engl J Med 1991;325:398-403.

5. Thompson CE, Damon LE, Ries CA, Linker CA. Thrombotic microangiopathies in the 1980s: clinical features, response to treatment, and the impact of the human immunodeficiency virus epidemic. Blood 1992;80:1890-5.
11. Clark WF, Rock GA, Buskard N, Shumak KH, LeBlond P, Anderson D, Sutton DM. Therapeutic plasma exchange: an update from the Canadian Apheresis Group. Ann Int Med 1999;131:453-62.

12. Fankouri F, Vernant JP, Veyradier A, Wolf M, Kaplanski G, Binaut R, Rieger M, Scheiflinger F, Poullin P, Deroure B, Delarue R, Lesavre P, Vanhille P, Hermine O, Remuzzi G, Grünfeld JP. Efficiency of curative and prophylactic treatment with rituximab in ADAMTS13 deficient thrombotic thrombocytopenic purpura: a study of 11 cases. Blood 2005;106:1932-7.

13. Bianchi V, Robles R, Alberio L, Furlan M, Lämmle B. Von Willebrand factor-cleaving protease (ADAMTS13) in thrombocytopenic disorders: a severely deficient activity is specific for thrombotic thrombocytopenic purpura. Blood 2002;100:710-3.

14. Moake JL. Thrombotic microangiopathies. N Engl J Med 2002;347:589-600.

15. Tsai HM. Deficiency of ADAMTS13 and thrombotic thrombocytopenic purpura. Blood 2002;100: 3839-40.

16. Mannucci PM. Thrombotic thrombocytopenic purpura: a simpler diagnosis at last? Thromb Haemost 1999;82: 1380-1. 
17. Cines DB, Konkle BA, Furlan M. Thrombotic thrombocytopenic purpura: a paradigm shift? Thromb Haemost 2000; 84:528-35.

18. Lankford KV, Hillyer CD. Thrombotic thrombocytopenic purpura: new insights in disease pathogenesis and therapy. Transfus Med Rev 2000;14:244-57.

19. Mori Y, Wada H, Gabazza EC, Minami N, Nobori T, Shiku H, Yagi H, Ishizashi H, Matsumoto M, Fujimura Y. Predicting response to plasma exchange in patients with thrombotic thrombocytopenic purpura with measurement of vWF-cleaving protease activity. Transfusion 2002;42:57280.

20. Raife T, Atkinson B, Montgomery R, Vesely S, Friedman K. Severe deficiency of VWF-cleaving protease (ADAMTS13) activity defines a distinct population of thrombotic microangiopathy patients. Transfusion 2004;44: 146-50.

21. Furlan M, Robles R, Galbusera M, Remuzzi G, Kyrle PA, Brenner B, Krause M, Scharrer I, Aumann V, Mittler U, Solenthaler M, Lämmle B. Von Willebrand factor-cleaving protease in thrombotic thrombocytopenic purpura and the hemolyticuremic syndrome. N Engl J Med 1998;339:157884.

22. Tsai HM, Lian EC. Antibodies to von-Willebrand factorcleaving protease in acute thrombotic thrombocytopenic purpura. N Engl J Med 1998;339:1585-94.

23. Moore JC, Hayward CP, Warkentin TE, Kelton JG. Decreased von Willebrand factor protease activity associated with thrombocytopenic disorders. Blood 2001;98: 1842-6.

24. Veyradier A, Obert B, Houllier A, Meyer D, Girma JP. Specific von Willebrand factor-cleaving protease in thrombotic microangiopathies: a study of 111 cases. Blood 2001;98: 1765-72.

25. Raife TJ, Lentz SR, Atkinson BS, Vesely SK, Hessner MJ. Factor V Leiden: a genetic risk factor for thrombotic microangiopathy in patients with normal von Willebrand factor-cleaving protease activity. Blood 2002;99: 437-42.

26. Rick ME, Moll S, Taylor MA, Krizek DM, White GC 2nd, Aronson DL. Clinical use of a rapid collagen-binding assay for von Willebrand factor cleaving protease in patients with thrombotic thrombocytopenic purpura. Thromb Haemost 2002;88:598-604.

27. Rizvi MA, Vesely SK, George JN, Chandler L, Duvall D, Smith JW, Gilcher RO. Complications of plasma exchange in 71 consecutive patients treated for clinically suspected thrombotic thrombocytopenic purpura-hemolytic uremic syndrome. Transfusion 2000;40:896-901.

28. McMinn JR, Thomas IA, Terrell DR, Duvall D, Vesely SK, George JN. Complications of plasma exchange in patients treated for clinically suspected thrombotic thrombocytopenic purpura-hemolytic uremic syndrome: an additional study of 78 consecutive patients. Transfusion 2003; 43:415-6.
29. Allford SL, Hunt BJ, Rose P, Machin S. Guidelines on the diagnosis and management of the thrombotic microangiopathic haemolytic anemia. Br J Haematol 2003;120:556-73.

30. Sadler JE, Moake JL, Miyata T, George JN. Recent advances in thrombotic thrombocytopenic purpura. Hematology 2004. Washington, DC: American Society of Hematology; 2004. p. 407-23.

31. Kappers-Klunne MC, Wijermans P, Fijnheer R, Croockewit AJ, van der Holt B, de Wolf JT, Löwenberg B, Brand A. Splenectomy for the treatment of thrombotic thrombocytopenic purpura. Br J Haematol 2005;130:768-76.

32. Arnold DM, Dentali F, Crowther MA, Meyer RM, Cook RJ, Sigouin C, Fraser GA, Lim W, Kelton JG. Systematic review: efficacy and safety of rituximab for adults with idiopathic thrombocytopenic purpura. Ann Intern Med 2007;146:2533.

33. Quintini G, Barbera V, Iannitto E, Mariani G. Potential strategies for the treatment of plasma exchange-resistant thrombotic thrombocytopenic purpura. Br J Haematol 2001;113:560-2.

34. Garvey B. Rituximab in the treatment of autoimmune haematological disorders. Br J Haematol Rev 2008;141:149-69.

35. Scaramucci L, Niscola P, Palumbo R, Giovannini M, Ales M, Tendas A, Cupelli L, Natale G, Dentamaro T, Perrotti AP, de Fabritiis P. Rapid response and sustained remission by rituximab in four cases of plasma-exchange-failed acute thrombotic thrombocytopenic purpura. Int J Hematol 2009;89:398-9.

36. Reddy PS, Deauna-Limayo D, Cook JD, Ganguly SS, Blecke C, Bodensteiner DC, Skikne BS, Sahud MA. Rituximab in the treatment of relapsed thrombotic thrombocytopenic purpura. Ann Hematol 2005;84:232-5.

37. Kameda T, Dobashi H, Kittaka K, Susaki K, Yamaoka G, Arai K, Tokuda M, Ishida T. Two cases of refractory thrombotic thrombocytopenic purpura associated with collagen vascular disease were significantly improved by rituximab treatment. Clin Rheumatol 2007;26:2159-62.

38. Yomtovian R, Niklinski W, Silver B, Sarode R, Tsai HM. Rituximab for chronic recurring thrombotic thrombocytopenic purpura: a case report and review of the literature. Br J Haematol 2004;124:787-95.

39. Chemnitz J, Draube A, Scheid C, Staib P, Schulz A, Diehl V, Söhngen D. Successful treatment of severe thrombotic thrombocytopenic purpura with the monoclonal antibody rituximab. Am J Hematol 2002;71:105-8.

40. Gutterman LA, Kloster B, Tsai HM. Rituximab therapy for refractory thrombotic thrombocytopenic purpura. Blood Cells Mol Dis 2002;28:385-91.

41. Sallah S, Husain A, Wan JY, Nguyen NP. Rituximab in patients with refractory thrombotic thrombocytopenic purpura. J Thromb Haemost 2004;2:834-6.

42. Ahmad A, Aggarwal A, Sharma D, Dave HP, Kinsella V, Rick ME, Schechter GP. Rituximab for treatment of refractory/ relapsing thrombotic thrombocitopenic purpura (TTP). Am J Hematol 2004;77:171-6. 
43. Koulova L, Alexandrescu D, Dutcher JP, O’Boyle KP, Eapen $\mathrm{S}$, Wiernik PH. Rituximab for the treatment of refractory idiopathic thrombocytopenic purpura (ITP) and thrombotic thrombocytopenic purpura (TTP): report of three cases. Am J Hematol 2005;78:49-54.

44. Millward PM, Bandarenko N, Chang PP, Stagg KF, AfenyiAnnan A, Hay SN, Brecher ME. Cardiogenic shock complicates successful treatment of refractory thrombotic thrombocytopenic purpura with rituximab. Transfusion 2005;45:1481-6.

45. Scott SM, Szczepieorkowski ZM. Rituximab for TTP. Am J Hematol 2005;80:878.

46. Yassa SK, Blessios G, Marinides G, Venuto RC. Anti-CD20 monoclonal antibody (Rituximab) for life-threatening hemolytic-uremic syndrome. Clin Transplant 2005;19: 423-6.

47. Daraibi K, Berg AH. Rituximab can be combined with daily plasma Exchange to achieve effective B-cell depletion and clinical improvement in acute autoimmune TTP. Am J Clin Pathol 2006;125:592-7.

48. Niewold TB, Alpert D, Scanzello CR, Paget SA. Rituximab treatment of thrombotic thrombocytopenic purpura in the setting of connective tissue disease. J Rheumatol 2006;33: 1194-6.

49. Scully M, Cohen H, Cavenagh J, Benjamin S, Starke R, Killick S, Mackie I, Machin SJ. Remission in acute refractory and relapsing thrombotic thrombocytopenic purpura following rituximab is associated with a reduction in IgG antibodies to ADAMTS-13. Br J Haematol 2006;136:451-61.

50. Heidel F, Lipka DB, von Auer C, Huber C, Scharrer I, Hess G. Addition of rituximab to standard therapy improves response rate and progression-free survival in relapsed or refractory thrombotic thrombocytopenic purpura and autoimmune haemolytic anaemia. Thromb Haemost 2007; 97:228-33.

51. Patino W, Sarode R. Successful repeat therapy with rituximab for relapsed thrombotic thrombocytopenic purpura. J Clin Apher 2007;22:17-20.

52. Rüfer A, Brodmann D, Gregor M, Kremer Hovinga JA, Lämmle B, Wuillemin WA. Rituximab for acute plasmarefractory thrombotic thrombocytopenic purpura. A case report and concise review of the literature. Swiss Med Wkly 2007;137:518-24.

53. Chow KV, Carroll R, Branley P, Nicholls K, Becker G, Hogan C. Anti-CD20 antibody in thrombotic thrombocytopenic purpura refractory to plasma exchange. Intern Med J 2007; 37:329-32.

54. Jasti S, Coyle T, Gentile T, Rosales L, Poiesz B. Rituximab as an adjunct to plasma exchange in TTP: a report of 12 cases and review of literature. J Clin Apher 2008;23:151-6.

55. Arici B, Trendelenburg M. Successful treatment of thrombotic thrombocytopenic purpura (TTP) with rituximab. Ther Umsch 2008;65:710-2.

56. Lalmuanpuii J, Yalamanchili K, Fircanis S, Nelson JC. Hypersensitivity to plasma exchange in a patient with thrombotic thrombocytopenic purpura. J Clin Apher 2009; 24:18-20.

57. Caramazza D, Quintini G, Abbene I et al. Rituximab for managing relapsing/refractory patients with idiopathic TTP-HUS. Blood Transfusion (DOI: 10.2450/2009.0101Published online: 07/08/2009, in press).

58. Pereira A, Mazzara R, Monteagudo J, Sanz C, Puig L, Martínez A, Ordinas A, Castillo R. Thrombotic thrombocytopenic purpura/haemolytic uremic syndrome: a multivariate analysis of factors predicting the response to plasma exchange. Ann Hematol 1995;70:319-23.

59. Guidelines for the use of fresh-frozen plasma, cryoprecipitate and cryosupernatant. Br J Haematol 2004;126:11-28.

60. McDonald V, Manns K, Mackie IJ, Machin SJ, Scully MA. Rituximab pharmacokinetics during the management of acute idiopathic thrombotic thrombocytopenic purpura. J Thromb Haemost 2010;8:1201-8.

61. Sadler JE. Von Willebrand factor, ADAMTS13, and thrombotic thrombocytopenic purpura. Blood 2008;112:11-8.

62. Ling HT, Field JJ, Blinder MA. Sustained response with rituximab in patients with thrombotic thrombocytopenic purpura: a report of 13 cases and review of the literature. Am J Hematol 2009;84:418-21.

63. Elliott MA, Heit JA, Pruthi RK, Gastineau DA, Winters JL, Hook CC. Rituximab for refractory and or relapsing thrombotic thrombocytopenic purpura related to immunemediated severe ADAMTS13-deficiency: a report of four cases and a systematic review of the literature. Eur J Haematol 2009;83:365-72.

64. Lämmle B, Kremer Hovinga JA, Alberio L. Thrombotic thrombocytopenic purpura. J Thromb Haemost 2005;3: 1663-75.

65. Ruiz J, Koduri PR, Valdivieso M, Shah PC. Refractory postpancreatitis thrombotic thrombocytopenic purpura: response to rituximab. Ann Hematol 2005;84:267-8.

66. Tsai HM, Shulman K. Rituximab induces remission of cerebral ischemia caused by thrombotic thrombocytopenic purpura. Eur J Haematol 2003;70:183-5.

67. Cataland SR, Wu HM. Immunotherapy for thrombotic thrombocytopenic purpura. Curr Opin Hematol 2005;12:359-63. 